\title{
MANAGING YOUR CARBON FOOTPRINT: IMPACTS AND OPPORTUNITIES ARISING FROM Alberta's Climate Change Legislation
}

\author{
DANA SARIC, ${ }^{*}$ LORNE CARSON, ${ }^{* *}$ \\ AND GUIDO BACHMANN ${ }^{* * *}$
}

\begin{abstract}
This article explores Alberta's climate change policies and laws in conjunction with parallel federal climate change measures. The authors provide an overview of the existing regulatory structure applicable to industrial carbon emissions, and an evaluation of the recent evolution of the regulatory structure. The comprehensive regulatory structure as a whole is then analyzed for its practical impacts across industries, and the authors identify a number of strategies for oil and gas producers, natural gas-fired electricity generators, renewable power project developers, and public entities to manage their performance within the new Alberta governance model for climate change management.
\end{abstract}

\section{TABLE OF CONTENTS}

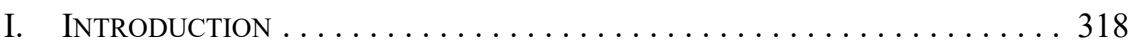

II. OVERVIEW OF AlBerta's PRE-EXISTING

Climate Change Legislative Framework . . . . . . . . . . . . . . . . . . 319

A. Historic Regulatory Structure: The Climate Change

AND EMISSIONS MANAGEMENT ACT AND ITS OPERATIVE

REGULATION, THE SPECIFIED GAS EMITTERS REGULATION . . . . . . . 319

B. INTERIM 2015 SPECIFIED GAS EMITTERS

REGULATION AMENDMENTS . . . . . . . . . . . . . . . . . 322

C. Future Transition to OUtPut-BASED

ALLOCATION OF EMISSIONS COSTS UNDER

THE SPECIFIED GAS EMITTERS REGULATION _............. 323

D. CRitical AsSESSMENT OF THE

Pre-Existing Legislation . . . . . . . . . . . . . . . . . . . . . . . . . . 324

III. ReCENT DEVELOPMENTS IN THE PROVInCIAL RegUlatory

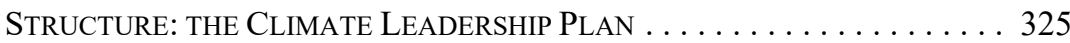

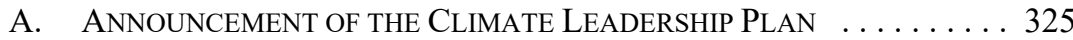

B. IMPLEMENTATiON of the Climate LeAdership Plan . . . . . . . 330

IV. Complementary Legislative DeVelopments

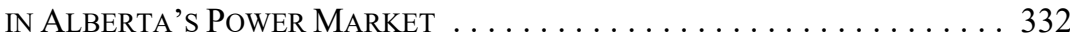

A. Alberta's UniQue Regulatory Model . . . . . . . . . . 332

B. Promotion of Renewable GeNERATING CAPACITY

THROUGH GOVERNMENT PROCUREMENT OF

RENEWABle ENERgy CRedits AND Power $\ldots \ldots \ldots \ldots \ldots . \ldots 333$

C. PROMOTION OF ELECTRICITY SUPPLY RELIABILITY

Via TRansition to a Capacity Market Model . . . . . . . . 334

* $\quad$ Associate, Osler, Hoskin \& Harcourt LLP, Calgary, Alberta.

*** Partner, Osler, Hoskin \& Harcourt LLP, Calgary, Alberta.

*** $\quad$ Vice President, Operations, Kineticor Resource Corp., Calgary, Alberta. 
V. Overview of Canada’s Federal Climate

MANAGEMENT REGULATORY STRUCTURE . . . . . . . . . . . . . . . . . . 336

VI. INTERPLAY OF REGULATORY SCHEMES

BETWEEN LEVELS OF GOVERNMENT . . . . . . . . . . . . . . . . . . . 338

A. FEDERAL FrameWORK UNLIKELY TO IMPOSE

SIGNIFICANT ADDITIONAL COSTS AND CONSTRAINTS

ON AlBERTA INDUSTRY . . . . . . . . . . . . . . . . . 338

B. APPROPRIATENESS OF DUAL LAYERS OF

CARbon Regulation . . . . . . . . . . . . . . . . . . . . 338

VII. INDUSTRY IMPLICATIONS: MANAGING

Carbon Footprints on Shifting Policy Ground . . . . . . . . . . . . 340

A. Carbon Auditing and Proactive Carbon Planning . . . . . . 340

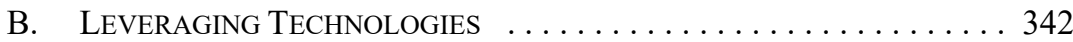

C. InVESting in Renewable Power . . . . . . . . . . . . . . 344

D. PARTICIPATION IN THE EMISSION OfFSET MARKET . . . . . . . . . 345

E. RELying ON Alternative REgUlatory StRUCTURES . . . . . . . . 347

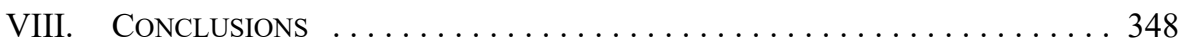

\section{INTRODUCTION}

Climate change presents environmental, political, social, and economic challenges worldwide. Keen to be seen at the forefront of climate policy leadership, and eager to mitigate negative attention from its carbon-intensive industries, Alberta continues to be a trailblazer in the climate change regulatory space. The Government of Canada has also recently joined the movement to be viewed as a climate policy leader on the international stage with its announcement of a national climate change policy framework. ${ }^{1}$

Canada's new frontier of climate change management resulting from federal and provincial policy measures will increase dependence on renewable power production and is geared to rely heavily on our plentiful natural gas resources rather than coal-fired production. At the same time, carbon policies will increasingly tax and constrain operations in the oil and gas industry, particularly the carbon-intensive oil sands sector.

Although Canada's federal framework is intended to provide a policy umbrella and minimum carbon pricing backstop for all industry players across the country, each province and territory bears responsibility for designing and implementing its own regulatory regime. Alberta, as an early adopter of climate change legislation, has designed a jurisdictionally isolated "made in Alberta" approach which impacts industry players with multi-jurisdictional operations. $^{2}$

Both the federal and provincial strategies are intended to provide policy direction and certainty. However, those entities impacted by climate change policies are required to

1 Government of Canada, "Pan-Canadian Framework on Clean Growth and Climate Change: Canada's Plan to Address Climate Change and Grow the Economy" (2016), online: <https://www.canada.ca/ content/dam/themes/environment/documents/weather1/20170125-en.pdf $>$ [Federal Framework].

2 Government of Alberta, "Climate Leadership Plan," online: $<$ https://www.alberta.ca/climate-leadershipplan.aspx $>$. 
operate and make long-term investment decisions in real time, despite the ongoing announcement of specific legislative reforms and evolving identification of the commercial consequences of these reforms on the economic environment in Alberta.

As there are a variety of approaches to carbon management in Canada, large greenhouse gas emitters will be challenged to find the most efficient and cost-effective ways to comply with the diverse and still-evolving regulations. Industrial greenhouse gas emissions from Alberta facilities represent a significant share of the national total due to the province's large energy industry and electricity base. As a result, the strategic reactions of Alberta's fossil fuel and electricity industry participants to Alberta's climate policy framework will be important in shaping practical and legal outcomes for the nation as a whole.

This article summarizes and assesses climate change policies and laws introduced in Alberta, in conjunction with parallel federal climate change measures. The impacts of the comprehensive regulatory structure on the oil and gas and power production industries in Alberta, as well as other private and public enterprises, are then discussed. Finally, strategies to optimize performance within the new governance models for climate change management are addressed.

\section{Overview of Alberta's Pre-Existing Climate Change Legislative Framework}

\section{A. Historic Regulatory Structure: The Climate Change AND EMISSIONS MANAGEMENT ACT AND ITS OPERATIVE REGULATION, THE SPECIFIED GAS EMITTERS REGULATION}

Despite its media reputation as an environmental laggard, Alberta has historically been a Canadian leader in managing climate change, and greenhouse gas emissions in particular. In 2007, Alberta became the first jurisdiction in North America to require industrial greenhouse gas emitters to reduce their emissions. The operative legislation for this requirement is the Climate Change and Emissions Management Act. ${ }^{3}$

The CCEMA sets a goal of a reduction of emissions of "specified gases"4 relative to Alberta's gross domestic product by 50 percent from 1990 emissions levels by $2020,{ }^{5}$ and implements a cap-and-trade scheme as a means to incentivize the necessary emissions reductions. ${ }^{6}$ However, unlike the absolute cap on emissions adopted in Ontario, ${ }^{7}$ Alberta has opted for an intensity-based reductions mechanism. This method measures the amount of carbon dioxide or equivalent output per unit of economic productivity, and then requires carbon emitters to gradually reduce their emissions relative to their respective production.

\footnotetext{
SA 2003, c C-16.7 [CCEMA].

Specified gases are prescribed in the Schedule to the Specified Gas Emitters Regulation, Alta Reg 139/2007 [SGER].

CCEMA, supra note 3 , s 3(1).

Ibid, s 5 .

Adrian Morrow, "Ontario Set to Tackle Climate Change With Cap-and-Trade Launch on Jan 1," The Globe and Mail (27 December 2016), online: $<$ https://beta.theglobeandmail.com/news/national/ontarioset-to-tackle-climate-change-with-cap-and-trade-launch-on-jan-1/article33440779/?ref=http://www.the globeandmail.com\&>.
} 
Several regulations implement the administration and enforcement of the CCEMA targets. The main mechanism by which the CCEMA is implemented is the Specified Gas Emitters Regulation. ${ }^{8}$ As discussed further below, the SGER was amended in 2015 and is expected to undergo further changes in the future.

The SGER provides the methodology by which a specified gas-emitting facility can calculate its baseline emissions intensity, and creates the requirement for each established facility to decrease its productivity-adjusted net emissions intensity by 20 percent relative to the facility's baseline emissions intensity (though this requirement was initially 12 percent). ${ }^{9}$ Notably, a facility under the SGER is only compared to its own historical emissions profile and not to its peers. ${ }^{10}$ Due to the intensity-based nature of the regime, facilities can increase their absolute emissions from year to year, so long as their per-unit emissions level is reduced by the legislated amount.

Also of note is the fact that the SGER only applies to large industrial emitters. Facilities which have annual emissions at or greater than 100,000 tonnes of carbon dioxide or equivalent emissions per year are subject to the regulation, while all others are excluded. ${ }^{11}$ Reported industrial emissions under the CCEMA framework account for approximately half of Alberta's total emissions. ${ }^{12}$

Pursuant to the SGER, a large emitter has four compliance options which its facility can use to meet its emission reduction obligations: (1) improvements in facility operating efficiency; (2) emission performance credits; (3) fund credits; and (4) emission offsets. ${ }^{13}$

\section{IMPROVEMENTS IN FACILITY OPERATIONS}

The first and most obvious option for complying with a large emitter's SGER obligations is to reduce greenhouse gas emissions through operational efficiencies.

SGER, supra note 4. SGER was proclaimed into force on 20 April 2007, with the reduction targets taking effect on 1 July 2007.

Ibid, s 4.

Ibid, s 21(1).

Ibid, s 2. Facilities with over 50,000 tonnes of carbon dioxide or equivalent emissions are subject to a reporting requirement, but not a reduction requirement. See Alberta Environment and Parks, "Specified Gas Reporting Standard,"Version 8.0 (Edmonton: AEP, March 2014), online: <aep.alberta.ca/climatechange/guidelines-legislation/specified-gas-reporting-regulation/documents/SpecifiedGasReporting Standard-Mar2014.pdf $>$.

In 2013, the latest year for which data has been made available, 106 facilities fell within the scope of the SGER, and an additional 61 facilities fell within the CCEMA's mandatory specified gas reporting requirements. These facilities include those conducting oil sands operations (oil sands mining and upgrading, oil sands in situ extraction, and emissions from associated cogeneration activities), electric power generation, conventional oil and gas extraction, chemical manufacturing, pipeline transportation, natural gas distribution, and various manufacturing activities. In total, reported industrial emissions accounted for 49.7 percent of Alberta's total emissions in that year: Alberta Government, Alberta Greenhouse Gas Reporting Program 2013 Facility Emissions (Edmonton: Climate Change Office, 2016), online: < aep.alberta.ca/climate-change/reports-and-data/documents/2013ReportGreenhouseGas Emissions-Sep2016.pdf>.

SGER, supra note 4, Part 2. 


\section{EMISSION PERFORMANCE CREDITS}

A regulated facility that achieves reductions beyond those required by the SGER may credit those excess efficiencies and carry them forward for application by that facility in future years, apply them to other facilities operated by the same large emitter, or even serialize those reductions and trade them as emission performance credits on Alberta's emission performance credit registry. ${ }^{14}$

\section{FUND CREDITS}

Facilities which cannot meet their SGER emissions reduction requirements through operational efficiencies can opt to purchase fund credits from the Climate Change and Emissions Management Fund (the Fund). Each fund credit is equivalent to one tonne of carbon dioxide or equivalent and carries a fixed price set by legislation. Between 2007 and 2015 , the fund credit price was $\$ 15$. The fund credit price was raised to $\$ 20$ in 2016 and is currently set at $\$ 30 .^{15}$

Pursuant to the CCEMA, the Climate Change and Emissions Management Corporation (rebranded in 2016 as Emissions Reduction Alberta or the ERA) is a not-for-profit corporation operated at arm's length from the government, which manages monies raised by the Fund. ${ }^{16}$ The CCEMA requires that the ERA fund projects whose purposes are related to energy conservation and efficiency, carbon capture and storage, and other emissions reduction activities. ${ }^{17}$

Since the SGER was enacted in 2007, approximately $\$ 740$ million has been paid into the Fund through the purchase of fund credits, which represents almost half of all SGER compliance. $^{18}$

\section{EMISSION OFFSETS}

Large emitters who cannot meet their emissions reduction compliance targets through operational efficiencies (current, or carried forward as emission performance credits) and who do not want to purchase fund credits can instead purchase emission offsets.

Emission offsets are credits for reductions in greenhouse gas emissions created by facilities which do not fall within the scope of the SGER. Once generated and verified in

Government of Alberta, Technical Guidance for Offset Protocol Developers, version 4.0 (Edmonton: Alberta Environment and Sustainable Resource Development, 2013), s 8, online: <aep.alberta.ca/ climate-change/guidelines-legislation/specified-gas-emitters-regulation/documents/Technical GuideOffsetProject-Feb2013.pdf $>$ [Government of Alberta, Technical Guidance]. See also CSA Group, "Alberta Emissions Offset Registry" (2017), online: <www.csaregistries.ca/albertacarbonregistries/ eor_about.cfm $>$ [CSA Group].

15 Alberta Environment and Parks, "Industrial Emissions Managment" (2017), online: <aep.alberta.ca/ climate-change/programs-and-services/industrial-emissions-management.aspx $>$ [AEP, "Industrial Emissions Management]. See also Government of Alberta, "Fiscal Plan: Climate Leadership Plan" (2017) at 60 , online: $<$ finance.alberta.ca/publications/budget/budget2017/fiscal-plan-climate-leadershipplan.pdf $>$ [Government of Alberta, "Fiscal Plan"].

Emissions Reduction Alberta, "About ERA" (2017), online: <eralberta.ca/about-era/>.

CCEMA, supra note 3 , s $10(3)$.

AEP, “Industrial Emissions Management,” supra note 15. 
accordance with prescribed protocols, each emission offset is equivalent to one tonne of carbon dioxide or equivalent, and can be registered on the emission offset registry and purchased and applied by large emitters towards their SGER compliance. ${ }^{19}$

In order to qualify as a registered, tradable offset, a reduction must meet several criteria. The emissions reduction must, among other things: occur in Alberta; result from actions not otherwise required by law; be real, demonstrable, and quantifiable (hence the protocols); and be counted once for compliance purposes. ${ }^{20}$

Established protocols control who may register and trade carbon offset credits. There are currently 34 quantification protocols, as well as a detailed process for the development of new protocols. Notably, as of this writing 18 of these 34 emission offset protocols are under review, and an additional five have been terminated since their inception. ${ }^{21}$ Approved emission offset protocols include protocols relating to distributed renewable energy generation, solar electricity generation, wind-powered electricity generation, solution gas conservation, waste heat recovery, engine fuel management and vent gas capture, and enhanced oil recovery. ${ }^{22}$

While Alberta's emission offset registry provides a record of all offset transactions, it does not function like an exchange platform where buyers, sellers, and brokers can meet. Instead, emission offset trades are private, bilateral transactions, and the registry merely identifies the verified emission offsets available for sale. The price of fund credits effectively caps the price for an offset credit because there is no incentive to pay more for an offset credit than the fixed amount required for a fund credit, particularly given that accounting and transaction costs are associated with offset credits but not with fund credits.

"[O]ver 33 million carbon offset credits have been created and serialized in Alberta." 23 Overall, emission offsets represent 30 percent of all SGER compliance from implementation until the end of 2015. ${ }^{24}$ There is clearly room for growth in the offset market in Alberta. The ability of parties to negotiate the price of offset credits below the fund credit price means that they can remain a competitive alternative to purchasing credits from the Fund.

\section{B. INTERIM 2015 SPECIFIED GAS EMitTERS REgulation AMENDMENTS}

In June 2015, shortly after the New Democratic Party was elected as the provincial government under the leadership of Premier Rachel Notley, the government announced that

GER, supra note 4, s 7. See also Alberta Environment and Parks, "Offset Credit System Protocols" (2017), online: <aep.alberta.ca/climate-change/guidelines-legislation/specified-gas-emitters-regulation/ offset-credit-system-protocols.aspx $>$ [AEP,"Protocols"].

SGER, ibid. See also Government of Alberta, Technical Guidance, supra note 14.

See AEP, "Protocols," supra note 19.

Ibid.

CSA Group, supra note 14.

Government of Alberta, "Specified Gas Emitters and Reporting 2016 Workshop" (14 March 2017), online: <aep.alberta.ca/climate-change/guidelines-legislation/specified-gas-emitters-regulation/docu ments/2016-SGER-WorkshopPresentation-Mar24-2017.pdf>. 
the SGER would be renewed for an additional two years, with several important amendments. ${ }^{25}$

Firstly, the overall emissions intensity reduction requirements were increased from 12 percent to 20 percent, effective as of January 1, 2017 (with an interim jump to 15 percent in 2016). ${ }^{26}$

Secondly, the fund credit price was increased from $\$ 15$ per tonne to $\$ 30$ per tonne, effective 1 January 2017 (with an interim jump to $\$ 20$ per tonne in 2016). ${ }^{27}$

Notably, the SGER is scheduled to expire 31 December $2017 .^{28}$ In the meantime, the consequence of the 2015 SGER Amendments is that the legislative framework for industrial carbon emissions remains the same, but with a slightly higher cost of doing business. The ceiling price on emission offsets will naturally increase towards the $\$ 30$ fund credit price. That, combined with the fact that more offsets will need to be bought to meet the more stringent reduction requirement, should mean greater demand for emission offset-generating projects in 2017 and going forward.

\section{Future Transition to OUTPUT-BASED Allocation of EMissions Costs UNDER THE SPECIFIED GAS EMITTERS REGULATION}

The SGER will be further revised as of 1 January 2018 to move towards an output-based allocation approach with sector-specific benchmarks for emissions-intensive, trade-exposed industries (such as oil and gas production). ${ }^{29}$

Currently, the requirement on facilities to make annual emissions reductions is based on a facility-specific historical baseline. This means that two facilities in the same industrial sector, which produce a similar or identical product, will have different emissions reduction obligations because of the idiosyncratic historical operating efficiency of each facility.

Under an output-based allocation approach, all facilities producing the same product or output will be compared using the same benchmark, such that the most emissions-intensive facilities will have the highest share of carbon levy obligations under the SGER, and the least emissions intensive facilities in the same sector may be free of carbon levies entirely because they compare so well to facilities producing the same or similar products.

A direct outcome of the implementation of output-based allocation mechanisms for nontaxed carbon emissions is that technologically or operationally less efficient plants - usually older facilities — will bear a disproportionate share of the carbon levies paid by their industry, as a penalty for being less carbon-efficient than their peers. This affects not only

Specified Gas Emitters Amendment Regulation, Alta Reg 104/2015 [2015 SGER Amendments].

SGER, supra note 4, s 4.

Government of Alberta, "Fiscal Plan," supra note 15 at 60.

SGER, supra note 4, s 30 .

Alberta Government, "Output-Based Allocation System Engagement" (2017), online: <https://www. alberta.ca/output-based-allocation-engagement.aspx $>$. 
oil extraction, upgrading, and refining industries, but also other facilities subject to the $S G E R$, including electricity production, natural gas processing, and transmission and chemical manufacturing.

The output-based allocation proposal is meant to create carbon competitiveness within industries and to encourage continual improvement, and at the time of writing, stakeholder engagement on how to implement the proposal is underway. ${ }^{30}$

\section{CRitical ASSESSMent OF THE Pre-Existing Legislation}

Even with the 2015 SGER Amendments, the CCEMA climate change management framework is subject to critical scrutiny. Some key areas of perceived weakness are the intensity-based cap, the limited scope of CCEMA's application, the ineffective price, and the jurisdictionally isolating rules of the framework.

A fundamental criticism of the structure is that emissions reductions are gauged on an intensity basis rather than an absolute basis. Critics have pointed out that intensity-based reduction requirements may lead to no net emissions reduction, as periods of economic growth would see net allowable emissions rise. ${ }^{31}$ However, with reduction targets commensurate with overall economic output, industry need not fear being fettered by absolute reduction targets which may have been put in place at the bottom of an economic cycle. Other than the introduction of the absolute cap on emissions from oil sands production activities, discussed below, the government appears to remain committed to not constraining industrial emissions on an absolute basis.

Many critics argued that the scope of the SGER's application is too limited, in that it applies only to large industrial emissions and not to heating or transportation fuels consumed by both residential and commercial end users. ${ }^{32}$ Further, the SGER's structure allows large industrial emitters to emit greenhouse gases freely, without cost, up to their allowable emissions intensity for a year.

The SGER has also been criticized for imposing too low of a carbon price and too low of an emissions reduction target to incent meaningful operational changes. ${ }^{33}$ In particular, low emissions reduction requirements are overly easy to meet with minor operational efficiencies, whereas low fund credit prices do not sufficiently incent significant year-over-year efficiency measures.

Some critics have noted that the "made in Alberta" nature of the SGER structure is jurisdictionally isolating for Alberta industry, and have suggested that national and international companies operating in Alberta would better be able to participate in Alberta's

Ibid.

See e.g. Dale Marshall, "Intensity-Based Targets: Not the Solution to Climate Change" (26 February 2007), online: <climateactionnetwork.ca/wp-content/uploads/2011/10/dsf-intensity-targets.pdf>.

See Andrew Read, "Climate Change Policy in Alberta" (July 2014), online: $<$ https://www.pembina.org/ reports/sger-climate-policy-backgrounder.pdf>. Ibid. 
climate change initiatives if the legislation permitted them to manage their carbon footprint in an integrated manner across jurisdictions (or, in other words, to make compliance requirements in Alberta better integrated with compliance options in other jurisdictions). ${ }^{34}$ The introduction of the Federal Framework, discussed below, mitigates this concern somewhat by promising equivalent treatment across Canada, but more could be done in the legislative structure to assist multi-jurisdictional emitters in Alberta with comprehensive carbon planning across jurisdictions.

On a more practical level, the SGER does not provide a great deal of certainty around the certification and use of emission offsets and emission performance credits. The SGER provides that emission offsets and emission performance credits are "revocable licenses" 35 and that "[n]othing in this Regulation ensures or guarantees the availability of emission offsets or emission performance credits." 36 The registries are not particularly intuitive, and any trades and their prices are not publicly reported. Further, the SGER relies on ex post verification, such that an emission offset or emission performance credit is first created, registered, sold, and only then verified, leaving buyers at risk of having purchased credits which do not ultimately work towards their SGER compliance because they cannot be verified or have expired. The result is administrative uncertainty for industrial emitters (and possibly aversion), and ultimately, emission offsets which trade at a discount to the simpler and guaranteed, but not market-driven, alternative of purchasing fund credits.

For the foregoing and other reasons, including a public relations need to gain social license for carbon-intensive pipeline projects, Alberta's new government was strongly motivated to make climate policy changes more drastic than the 2015 SGER Amendments.

\section{Recent Developments in the Provincial Regulatory Structure: The Climate Leadership Plan}

\section{A. Announcement of the Climate Leadership Plan}

The Government of Alberta announced a robust climate change leadership plan (the Climate Leadership Plan) on 22 November $2015 .{ }^{37}$ It is based on the recommendations of the province's Climate Change Advisory Panel (the Panel), whose report was released concurrently with the provincial government's press conference, ${ }^{38}$ and addresses a number of the perceived weaknesses of the SGER regulatory structure. The cornerstones of the new plan are: (1) an economy-wide carbon levy; (2) an accelerated phase-out of coal; (3) an absolute cap on oil sands emissions; and (4) a methane gas emissions reduction plan. ${ }^{39}$

Neil McCrank \& Alan L Ross, “Temperature Check: Alberta Makes Big Move on Carbon Emissions," Financial Post (25 June 2015), online: < business.financialpost.com/opinion/temperature-check-albertamakes-big-move-on-carbon-emissions $>$.

SGER, supra note 4, s $10(1)$.

Ibid, s 10(2).

"Alberta's Climate Change Strategy Targets Carbon, Coal, Emissions," CBC News (22 November 2015), online: <www.cbc.ca/news/canada/edmonton/alberta-climate-change-newser-1.3330153>; Government of Alberta, "Climate Leadership Plan," supra note 2.

38 Alberta, Climate Change Advisory Panel, Climate Leadership: Report to Minister (20 November 2015), online: $<$ https://www.alberta.ca/documents/climate/climate-leadership-report-to-minister.pdf $>$ [Panel Report].

Government of Alberta, "Climate Leadership Plan," supra note 2. 


\section{AN ECONOMY-WIDE CARBON PRICE}

Carbon pricing is the backbone of the Climate Leadership Plan. The SGER structure for large emitters, which maintains the previously existing $\$ 30$ per tonne levy on industrial carbon emissions, will remain in place for the time being. ${ }^{40}$ However, an additional carbon tax is levied on all Alberta consumers, including facilities which are too low-emitting to fall under the SGER and residential customers, which economy-wide price is to rise to $\$ 30$ per tonne by 2018 to match the SGER rates. ${ }^{41}$ The broader, economy-wide carbon price is expected to touch 78 to 90 percent of all emissions in the province; the largest proportion in Canada. ${ }^{42}$ The economy-wide carbon price introduced by the Climate Leadership Plan is a strong rebuttal to critics of the SGER's limited scope, but it has also increased the cost of conducting business in Alberta across industries.

The consequence is that facilities that were not subject to the SGER because they were not emitting enough, will now have to pay a carbon tax on all of their emissions. Facilities emitting less than 100,000 tonnes of carbon or equivalent per year may opt into the SGER structure rather than paying the new economy-wide carbon levy. Compliance options for subject facilities are the same as under the SGER structure.

The Climate Change Advisory Panel also recommended an annual escalator of 2 percent more than inflation, ${ }^{43}$ but it is not clear whether the government will adopt that recommendation. However, Premier Notley has announced that the carbon levy rate will be raised to meet the $\$ 50$ per tonne benchmark set by the federal government, discussed below. $^{44}$

A key feature of the Climate Leadership Plan is the pledge that all proceeds of the broader carbon tax would remain in and be put to work within provincial borders, through investment in green infrastructure (such as public transit), energy-efficiency programs, renewable energy research, development and investment (including the payment of emission offset contracts to be offered at auction for renewable power projects), and an adjustment fund. ${ }^{45}$ This fund would be used to help lower-income Albertans offset the cost increases of carbon pricing and to provide financial support to small businesses, First Nations, and those working in coal facilities subject to the accelerated phase-out of coal-fired power production. ${ }^{46}$ This fund is

Note that the Panel proposed a new Carbon Competitiveness Regulation which applies to both industrial emissions from large emitters and end-use emissions, but the dual-stream carbon pricing is in place until at least 2018. See Panel Report, supra note 38 at 31.

41 Government of Alberta, "Carbon Levy and Rebates," online: $<$ https://www.alberta.ca/climate-carbonpricing.asp $x>$.

42 See online: Solar West Conference $<$ solarwestconference.ca/wp-content/uploads/2017/05/SolarWestRobertHamaliuk-AlbertaClimateChangeOffice.pdf $>$.

43 Panel Report, supra note 38 at 6

44 Jeff Lewis, “Alberta to Phase in \$50-per-tonne Carbon Tax," The Globe and Mail (29 November 2016), online: </beta.theglobeandmail.com/report-on-business/industry-news/energy-and-resources/alberta-tophase-in-50-per-tonne-carbon-tax/article33096047/?ref=http://www.theglobeandmail.com\& $>$.

45 Government of Alberta, "Climate Leadership Plan," supra note 2.

46 Government of Alberta, "Climate Leadership Plan Will Protect Albertans' Health, Environment and Economy" (22 November 2015), online: <https://www.alberta.ca/release.cfm?xID=38885E74F7B63A62D-D1D2-E7BCF6A98D616C09> [Plan Announcement]. 
one of the legislative measures incidental to the Climate Leadership Plan which is designed to abate concerns about the impact of the levy on individuals and small businesses. ${ }^{47}$

Carbon pricing hits carbon-intensive oil and gas production activities quite hard. At over 25 percent of all emissions, the oil and gas industry is Canada's largest emitting industry and its fastest growing source of emissions. ${ }^{48}$ The oil sands sector alone is responsible for 8.5 percent of total Canadian emissions and over one quarter of Alberta's carbon emissions. ${ }^{49}$ Therefore, the oil and gas industry, and oil sands emitters in particular, will be responsible for a large and rapidly growing share of carbon taxes payable in the province. While carbon pricing imposes an additional layer of costs onto producers, it is important to note that many were already subject to rising carbon prices under the SGER, and some had been modeling much higher carbon prices into their forecast models for quite some time.

\section{ACCELERAted Phase-Out of COAL-Fired Generation AS A COMPLEMENTARY POLICY TO CARBON PRICING}

As a complement to the new economy-wide carbon price, the government announced that it would pursue a regulated, accelerated phase-out of coal-fired production, to be made possible by increased generation of renewable and gas-fired power.

Evidently, coal-fired power producers are the biggest losers of the Climate Leadership Plan. That said, only six of the newest coal-fired plants of the 18 in operation in the province were scheduled to be in operation past the 2030 coal phase-out deadline in any event, and the provincial government has negotiated compensation payments to the affected facility owners. The province is paying the operators of those plants, TransAlta Corp., ATCO Ltd., and Capital Power Corp., a total of \$97 million annually over 14 years, beginning in 2017 - a total of almost $\$ 1.36$ billion to be paid from proceeds of the carbon levy. ${ }^{50}$ Compensation payments for coal operators' stranded capital is intended to regulate the phaseout and ensure the funding of necessary facility maintenance in order to minimize shocks to price and ensure electricity supply reliability. ${ }^{51}$

Aside from the potential for natural gas retrofitting where economically viable, coal-fired power generation is being fully phased out and will no longer be contributing to Alberta's

47 In order to effect the rebates promised by Premier Notley during her announcement of the Climate Leadership Plan, the Climate Leadership Act, RSA 2016, c C-16.9 [CLA] amends the Alberta Personal Income Tax Act, RSA 2000, c A-30 to provide for rebates to consumers in respect of amounts paid pursuant to the CLA. If rebates offset the increased cost of heating, transportation fuels, and other consumer goods for 60 percent of Albertan households, it is not clear that the carbon levy will incent Albertans to reduce their greenhouse gas emissions. Whether the rebates are sufficient to cover increased consumer costs for low-income Albertans is also not clear. The CLA also amends the Alberta Corporate Tax Act, RSA 2000, c A-15 to reduce the small business tax rate from 3 percent to 2 percent. Environment and Climate Change Canada, "Canadian Environmental Sustainability Indicators: Greenhouse Gas Emissions" (Gatineau, QC: ECCC, 2017) at 8, online: <https://www.ec.gc.ca/ indicateurs-indicators/FBF8455E-66C1-4691-9333-5D304E66918D/GHG Emissions_EN.pdf>. Alberta Energy, "Facts and Statistics" (2017), online: <www.energy.alberta.ca/Oil Sañds/791.asp>. Geoffrey Morgan, "Alberta to Pay Three Power Companies \$1.36 Billion to Shut Their Coal-Fired Plants Early," Financial Post (24 November 2016), online: < business.financialpost.com/commodities/ energy/alberta-strikes-1-36-billion-deal-with-coal-companies-as-part-of-plan-to-shut-down-plantsearly>.

51 Ibid. 
low wholesale power prices beyond $2030 .{ }^{52} \mathrm{Also}$, until their eventual phase-out, all coal-fired generators will be paying the carbon levy on their emissions, which favours the dispatch of lower-emitting and more efficient natural gas-fired production.

One third of the new-found capacity in the province's electrical grid is targeted to be filled by renewable power. ${ }^{53}$ This policy announcement was solidified by the enactment of a 30 percent renewables target in the Renewable Electricity Act. ${ }^{54}$ As further evidence of the government's commitment to this target, the government is running an auction to provide limited financial support on a technology-neutral basis in the form of indexed renewable energy credits, which is discussed in greater detail below. ${ }^{55}$

\section{Absolute CAP on CARbon Emissions From Oil SANDS Production AS A COMPLEMENTARY POLICY TO CARBON PRICING}

As another complement to the new carbon pricing structure, the government has created an absolute cap on permissible carbon emissions from all oil sands production in the province of 100 megatonnes $(\mathrm{Mt})$ per year, not including cogeneration related to oil sands production or upgrading. ${ }^{56}$

This announcement was largely unexpected and of great significance, because oil sands production in the province is currently responsible for approximately $70 \mathrm{Mt}$ of annual emissions ${ }^{57}$ For new projects with top-quartile or better potential emissions performance under the SGER with its sector-specific, output-based allocation approach, the new treatment may provide significant cost and public relations advantages, but for those with high prospective emissions intensities (or significant risk of such an outcome), the policy will magnify carbon compliance costs and may make such projects less attractive.

An absolute cap on oil sands emissions is a significant departure from the intensity-based cap under the SGER, and risks stymying the development of future oil sands projects. Given that the industry currently emits 70 percent of its new capped emissions allotment, and there exist additional approved, but not yet operational, projects that will contribute to such emissions, then unless there are significant efficiency-based emissions reductions from existing projects, new projects will have to compete for the remaining capacity in order to come online. Companies may have incentives to seek regulatory approval for new projects before the absolute cap is reached. An absolute cap without the opportunity to buy or trade emissions capacity could also stifle the development of new projects.

A corollary implication of this hard cap component of Alberta's Climate Leadership Plan is the impediment to new market entrants. Existing oil and gas producers will not invest in emissions-reducing technologies and innovation at great cost simply to provide enough room

Ibid.

Government of Alberta, "Climate Leadership Plan," supra note 2.

SA 2016, c R-16.5, s 2(1) [REA].

See supra note 53 .

Government of Alberta, "Capping Oil Sands Emissions," online: <https://www.alberta.ca/climateoilsands-emissions.aspx>.

Ibid. 
in the cap for the permitting and operation of a competitor's project. Hence, a narrowing of market participation may occur as a result of the absolute cap on oil sands emissions.

\section{NeW Methane Emissions Reduction StRategy}

The fourth prong of the Climate Leadership Plan is a targeted reduction of methane emissions from oil and gas operations by 45 percent from 2014 levels, by $2025 .^{58}$ The rationale for targeting methane emissions reductions on top of disincentivizing greenhouse gas emissions through carbon pricing is that methane is 25 times more potent than carbon dioxide in terms of climate change impact. ${ }^{59}$ The oil and gas industry is by far the largest source of methane emissions in Canada and in Alberta. ${ }^{60}$

Not much detail has been offered to date regarding the new methane emissions reduction strategy.

New facilities in the province will be subject to emissions design standards, ${ }^{61}$ which will place them at a disadvantage relative to older facilities not subject to similar restrictions; conversely, those newer facilities will likely perform well in an output-based allocation system and have lower SGER or successor legislation-related compliance costs. Further, new regulations are expected to take effect in 2020 regarding the measurement and reporting of methane emissions, leak detection and repair requirements. ${ }^{62}$

Two emission offset protocols currently exist to incentivize methane reductions in the oil and gas sector by creating the potential for emission offset generation and sales from solution gas conservation or efficient equipment investment activities. ${ }^{63}$ Further, the ERA has earmarked $\$ 40,000,000$ to fund the advancement of commercial methane reduction technologies. $^{64}$

The Panel suggested a hybrid regulatory and market-based approach to reducing methane emissions. ${ }^{65}$ The authors posit that a market-based approach, such as an expansion of methane focused emission offset protocols being developed to reward methane emissions reductions, would be incrementally more effective than command-and-control regulatory measures for the already beleaguered oil and gas industry in Alberta.

Plan Announcement, supra note 46.

Alberta Energy Regulator, "Methane Reduction" (2017), online: <https://www.aer.ca/aboutaer/spotlight-on/methane-reduction>.

In Alberta, the oil and gas industry is the largest source of methane emissions, in which methane emissions account for 70 percent of provincial methane emissions and 25 percent of all carbon dioxide equivalent emissions from the upstream oil and gas sector. Forty-eight percent of upstream methane emissions are from direct venting or venting from equipment, 46 percent are from fugitive emissions or leaks, and 6 percent are from flaring or other sources. See Government of Alberta, "Reducing Methane Emissions," online: $<$ https://www.alberta.ca/climate-methane-emissions.aspx $>$.

AER, "Methane Reduction," supra note 59.

Government of Alberta, "Reducing Methane Emissions," supra note 60.

Ibid.

Government of Alberta, "New 'ERA' of Climate Innovation Targets Methane Pollution” (21 October 2016), online: <https:/www.alberta.ca/release.cfm?xID=43663196ecdb0-d667-25d7-74c379b20d4bc $055>$.

Panel Report, supra note 38 at 7. 


\section{B. Implementation OF The Climate Leadership Plan}

Although the Climate Leadership Plan sets instructive policy guidance for climate change in Alberta, the legislative tools by which its policy goals will be achieved are still being rolled out.

For instance, the hard cap on oil sands emissions has been introduced via the Oil Sands Emissions Limit Act (Bill 25) ${ }^{66}$ since 1 November 2016, but decisions about how to enforce the law and build out legislation will be made in 2017, after an 18-member Oil Sands Advisory Group reports to the government on how the cap should be maintained. ${ }^{67}$ Similarly, the regulations surrounding the methane emissions reduction strategy have yet to be delineated. However, the crux of the Climate Leadership Plan, the carbon levy, has been introduced and is already in effect.

On 24 May 2016, Alberta's Environment and Parks Minister, Shannon Phillips, introduced the Climate Leadership Implementation Act (Bill 20), ${ }^{68}$ which implements the carbon levy on Albertans and Alberta businesses that the government previously announced under its Climate Leadership Plan. Bill 20 includes two new acts, the $C L A^{69}$ and the Energy Efficiency Alberta $A c t,{ }^{70}$ as well as amendments to the Alberta Corporate Tax Act, ${ }^{71}$ the Alberta Personal Income Tax Act, ${ }^{72}$ and the CCEMA. ${ }^{73}$

The CLA applies a carbon levy to all sales and imports of fuel, subject to certain exemptions. ${ }^{74}$ The specific rates depend on the type of fuel, but all are set on the basis of $\$ 20$ per tonne of carbon dioxide or equivalent in 2017 , rising to $\$ 30$ per tonne in $2018 .^{75}$ The carbon levy applies throughout the fuel supply chain, including at the following points: at the point of purchase; when fuel is being imported; and at the point of removal of fuel from a refinery, terminal, plant, or oil or gas battery. ${ }^{76}$ Additionally, the carbon levy will also eventually apply when the recipient flares or vents the fuel, or engages in a prescribed activity. ${ }^{77}$

The CLA, along with its regulations, fleshes out some technical details relating to the CLA's carbon levy, including exemptions to the levy. ${ }^{78}$ A consumer is exempt from paying

Bill 25, Oil Sands Emissions Limit Act, 2nd Sess, 29th Leg, Alberta, 2016 (assented to 14 December 2016), SA 2016, c O-7.5.

Justin Giovannetti, “Alberta Bill Would Cap Oil Sands Greenhouse Gas Emissions," The Globe and Mail (1 November 2016), online: $<$ https://www.theglobeandmail.com/news/national/alberta-bill-wouldcap-oil-sands-greenhouse-gas-emissions/article32638790>.

Bill 20, Climate Leadership Implementation Act, 2nd Sess, 29th Leg, Alberta, 2016 (assented to 13 June 2016), SA 2016, c 16.

Supra note 47.

SA 2016, c E-9.7.

Supra note 47.

Supra note 47.

Supra note 3.

CLA, supra note 47 , ss 4-10.

Government of Alberta, "Carbon Levy and Rebates," supra note 41.

CLA, supra note 47, ss 4(2), 26.

Alberta Treasury Board and Finance, Information Circular CL-1, "Overview of Carbon Levy on Fuel" (2 December 2016), online: <www.finance.alberta.ca/publications/tax rebates/carbon-levy/CL-1.html $>$. The CLA, supra note 47, s 15(1) contains several exemptions from the carbon levy, including: fuel purchased under a carbon levy exemption certificate or a licence for exemption issued by the Minister; fuel used by the consumer in the operation of a specified gas emitter as set out in the regulations; fuel used by the consumer before 2023 as set out in the regulations; fuel used for farming operations; and 
a carbon levy on fuel used in the operation of a facility to which the SGER applies, if the emissions from the fuel are direct emissions and are marked as such. ${ }^{79}$ This means that a large industrial emitter, such as an oil sands producer or power plant, will not be subject to both SGER compliance costs for emissions above its annual emissions limit and the CLA carbon price applicable to all emissions. Another notable exemption permits consumers to avoid the carbon levy until 2023 on all fuel that is used, flared, or vented in a production process, such as the drilling, completion, or operation of an oil or gas well. ${ }^{80}$

The CLA creates a registration requirement, which prohibits activities including producing and processing fuel, selling and importing fuel, and removing fuel from a refinery or plant, without registration. ${ }^{81}$ This is a new regulatory requirement for those in the oil and gas industry, including producers, oil refiners, and gas stations.

Under the CLA, revenues generated through the carbon levy may only be used for specified purposes, including: initiatives related to reducing greenhouse gas emissions; supporting Alberta's ability to adapt to climate change; and providing rebates or adjustments related to the carbon levy to consumers, businesses, and communities. ${ }^{82}$ Though it has a very permissive breadth, the restriction on the uses of the revenue generated from the carbon levy is consistent with Premier Notley's prior commitment that the proceeds of the carbon tax would remain in and be put to work within Alberta. ${ }^{83}$

Bill 20 also amended the CCEMA. The CCEMA remains in force and provides a regulatory regime which continues to apply to all large industrial emitters, but through the new amendment, the government has somewhat broadened the scope of the uses of funds of the CCEMA ${ }^{84}$ Given the tightening of reduction requirements and increase of fund credit per unit costs through the 2015 SGER Amendments, ${ }^{85}$ it is anticipated that the ERA's funds available for investment will grow considerably. The appropriate investment of those funds will be a strong indicator of the government's effectiveness in delivering on the Climate Leadership Plan's objectives going forward.

fuel that is not put into a fuel system that produces heat or energy (that is, fuel products not used as a fuel, such as when used in an industrial process or as a solvent or diluent).

Climate Leadership Regulation, Alta Reg 175/2016, s 11 [CLR].

CLA, supra note 47, s 15(1)(d); ibid, ss 11(2)-(3).

CLA, ibid, s 27.

Ibid, s 3(2).

Plan Announcement, supra note 46. In the November 2015 announcement of the Climate Leadership Plan, Premier Notley did not rule out using the revenue to pay down public debt in the future; however, the CLA does not currently allow for revenue from the carbon levy to be used for debt repayment or general expenditures. That being said, the permitted use in section 3(2)(a) of the CLA, supra note 47, for "initiatives related to reducing emissions of greenhouse gases or supporting Alberta's ability to adapt to climate change" is fairly broad and could permit a wide range of spending initiatives, including compensation payments to affected communities, spending on green infrastructure, and other applications of funds which were announced together with the Climate Leadership Plan.

For instance, to include education initiatives, and paying government salaries and costs incurred in relation to supporting Alberta's climate change programs: see CCEMA, supra note 3, s 10(3). Supra note 25 . 


\section{COMPLEMENTARY Legislative DEVElopments in Alberta’s Power MARKet}

\section{A. Alberta's UniQue Regulatory Model}

The implications of the Climate Leadership Plan on the power industry in Alberta, and indirectly to all provincial business sectors, must be understood within the context of the province's electricity market. Alberta's electricity market is operated using a unique regulatory model.

Unlike jurisdictions with fixed price or guaranteed-return power pricing, Alberta hosts a deregulated energy-only wholesale power market, in which generators are paid only for the electricity they actually sell at the price prevailing in the applicable hour. ${ }^{86}$ The framework features the Power Pool of Alberta, which dispatches energy through the province through a real time spot wholesale power market. Independent facilities which generate power, through coal combustion, renewable power generation, or otherwise, offer their power into the system at a particular price for each hour, and the price which each generator receives is determined by the offer price of the last generating unit dispatched to the supply system load in that hour. This competitive model for matching hourly supply and demand results in a variable "spot" pool price. ${ }^{87}$

Alberta's wholesale electricity model promotes competition and cost efficiency. However, the spot wholesale energy market has made it difficult to incentivize new power generation from small-scale and renewable generators. Because it is a spot market, generators must build capital-intensive plants and operate them over a long period without any guarantee that they will be capable of recouping their costs based solely on the pool price applicable to the times they are able to bid into the power pool. Most new generation in this environment has been balance sheet-financed, as a prolonged trend of low power pool prices and price unpredictability has made it virtually impossible for generators to project finance. A spot market makes it difficult for electrical power producers to secure project financing, because lenders cannot rely on long-term fixed prices or similar guaranteed revenue streams.

Concurrently with the announcement of the Climate Leadership Plan, the Panel recommended maintaining Alberta's deregulated wholesale electricity-only market, and incenting new renewable generation by offering limited financial support through fixed-price renewable energy credits while continuing to require all power producers to rely on the

86 Contrast with: (a) Ontario, where electrical generation is centrally planned and a Crown utility enters into long-term 20-30 year fixed price contracts with private generators, and (b) Saskatchewan and other western provinces, which follow a cost-of-service model where electricity rates are set based on the operating costs borne by power generators, plus an allowed rate of return. Alberta's power market regulatory model is unique to each jurisdiction in North America except for Texas. For details on Ontario, see Michael Wyman, "How to Free Ontario's Electricity Market," Financial Post (15 September 2014), online: <business.financialpost.com/opinion/ontario-power-electricity-prices>. For Saskatchewan, see SaskPower, "The Cost of Service Model," online: <www.saskpower.com/wp-content/ uploads/COSReview_Summary_Jan2017.pdf>. For Alberta, see Alberta Electric System Operator, "Guide to Understand̄ing Alberta's Electricity Market," online: <https://www.aeso.ca/aeso/training/ guide-to-understanding-albertas-electricity-market/>.

87 Alberta Electric System Operator, "Market and System Reporting," online: <https://www.aeso.ca/ market/market-and-system-reporting/>. 
variable power pool price for energy ${ }^{88}$ The Panel's proposal arguably provided insufficient price certainty to incent sufficient new renewable power generation, and it offered no incentive for additional gas-fired generation capacity. Consequently, the power industry pushed back on the proposal.

The introduction of the carbon levy, the mandatory coal phase-out, and the enactment of ambitious renewable energy targets have triggered important knock-on effects to the electricity supply model in Alberta. The two chief elements of the modified electricity program are the competitive process by which the government intends to procure renewable generating capacity, and the announced introduction of capacity payments to incent supply reliability. ${ }^{89}$

\section{B. Promotion of Renewable Generating CAPACity Through Government Procurement of Renewable Energy Credits ANd Power}

On 3 November 2016, the Government of Alberta announced its endorsement of the recommendations of the Alberta Electric System Operator (AESO) to promote renewable energy development under a new Renewable Electricity Program. ${ }^{90}$ The REA legislated a target of 30 percent of electricity generation capacity in Alberta to come from renewable sources by $2030 .{ }^{91}$ In order to actually incent procurement towards this legislated target, the Renewable Electricity Program to be designed and run by the AESO will entail a series of competitions for the sale of renewable energy credits (that is, emission offsets) from new or expanded renewable energy generators to the provincial government. ${ }^{92}$ Partly in response to industry pushback, the program will use an indexed renewable energy credit (or indexed REC) methodology. ${ }^{93}$

Indexed RECs are purchased by the government under a what is essentially a contract for differences model. Under an indexed REC approach, renewable energy generators bid in a competitive process for long-term government contracts based on the price at which they estimate they can operate new renewable generation projects on a per megawatt hour basis (\$/MWh) (the strike price). If the pool price the generators receive in the market is less than their strike price, the generator receives a payment from the AESO for the difference, but if the pool prices rise above the strike price the generator pays the AESO. ${ }^{94}$

The first competitive process was announced in late 2016 and is scheduled to be completed by year-end 2017. At the time of writing, prospective bidders are proceeding

Panel Report, supra note 38.

See Government of Alberta, "Renewable Electricity Program" (2017), online: $<$ https://www.alberta.ca/ renewable-electricity-program.aspx>; Government of Alberta, "Electricity Capacity Market," online: $<$ https://www.alberta.ca/electricity-capacity-market.aspx $>$.

Government of Alberta, "Renewable Electricity Plan to Create Jobs, Spur Investment" (3 November 2016), online: <https://www.alberta.ca/release.cfm?xID=43752abfe959b-9ad9-9e3c-dbfcf5b5ca13c24c > [Government of Alberta, "Renewable Energy Plan"].

REA, supra note 54 , s 2 .

Government of Alberta, "Renewable Energy Plan," supra note 90.

Alberta Electric System Operator, "Background and Resources," online: $<$ https://www.aeso.ca/market/ renewable-electricity-program/background-and-resources/>. Ibid. 
through a request for qualifications stage. The government intends to procure $400 \mathrm{MW}$ of renewable power generation capacity of the targeted 5,000 MW in this first competition. ${ }^{95}$

Successful bidders will sign a 20-year Renewable Energy Support Agreement with the AESO which requires the project to be in operation by year-end 2019 and supported by performance security. ${ }^{96}$ Given the financial support requirements and short construction timeline for the first competitive process, as well as equity funding and tangible net worth tests specified in the AESO's request for qualification process, many speculate that only experienced and well-funded renewable generators will successfully participate in the first round.

In exchange for support payments, renewable projects must transfer all renewable attributes (that is, emission offsets) generated by the project to the AESO, as well as 50 percent of any other government funding which may be received by the project. The support payments made by the AESO will be funded by government revenue from SGER fund credits. $^{97}$

The first competitive process will be a technology-neutral process in which wind, solar, and other renewable sources will compete on equal footing. Given the lower levelized cost of utility-scale wind-powered electricity over solar, geothermal, and other technologies, it is expected that most if not all of the successful bidders will be wind farm operators. The government has indicated in stakeholder engagement sessions that future iterations of the Renewable Electricity Program auctions may be technology-selective, in order to forcibly diversify the renewable technologies being brought onto the power grid. Such a decision would benefit solar-powered generation in the province, which currently benefits from a strong solar resource in the province, but represents a miniscule proportion of generating capacity and is stifled by a lack of policy framework such as rebates and other incentives to pursue this costlier form of renewable power. ${ }^{98}$

The government has also indicated that future rounds of renewable procurement might not be based on the indexed REC model. ${ }^{99}$

\section{Promotion of Electricity SuPPly Reliability Via Transition to a CAPACITY Market MOdel}

On 23 November 2016, the provincial government announced that Alberta will transition to a capacity market model instead of requiring generators to rely solely on the energy-only

Alberta Electric System Operator, "AESO Renewable Electricity Program: Key Provisions of the Renewable Electricity Support Agreement" (10 November 2016), online: <https://www.aeso.ca/ assets/Uploads/REP-RESA-Term-Sheet-for-Stakeholder-Comments-10-11-2016.pdf> [AESO, "Key Provisions"]. For the full draft form of an agreement, see Alberta Electric System Operator, "Draft Renewable Electricity Support Agreement" (28 April 2017), online: <https://www.aeso.ca/assets/ Uploads/Draft-RESA.pdf>.

97 AESO, "Key Provisions," ibid.

98 At time of writing, Alberta has an installed solar generating capacity of only 20,011 kW. See Solar Energy Society of Alberta, online: <https://solaralberta.ca/ .

99 Alberta Electric System Operator, "Renewable Electricity Program Recommendations" (May 2016), online: $<$ https://www.aeso.ca/assets/Uploads/AESO-RenewableElectricityProgramRecommendationsReport.pdf $>$. 
market for their revenue streams. Rather than paying generators only for the energy they produce, a capacity market pays companies both for the capacity they could offer the market, even when their facilities are not operating, plus the price they receive for the electricity they generate when operational. ${ }^{100}$

The AESO is currently engaging stakeholders to determine the design of the capacity market. First procurement is expected to begin in 2019 and the capacity market is expected to be in place by $2021 .{ }^{101}$ While the details have yet to be determined, a capacity market will need to be carefully designed in order to promote new generating capacity and supply reliability while remaining financially efficient for Alberta ratepayers.

It is believed that, in addition to paying generators for the electricity sold, some generators will be able to receive payment for available capacity pursuant to one to five year (or other relatively short-term) AESO contracts. ${ }^{102}$ This provides generators with not only an additional revenue stream, but also an increased proportion of revenue certainty which may be leveraged to obtain project financing or more attractive financial hedges. However, there is some ongoing uncertainty in the market due to the fact that project financing lenders typically seek revenue certainty in contract terms of longer than merely three to five years.

It is not yet evident what the capacity payment price will be, or whether different forms of power generation will be paid different rates depending on the contribution of that capacity to the reliability objective. If intermittent renewable power sources such as wind are able to compete in Alberta's future capacity market model, those projects will benefit from three separate revenue streams: variable price energy sales, short-term fixed capacity payments, and long-term emission offset sales (either through the government's indexed REC contracts or by private emission offset sales).

Nonetheless, both natural gas and renewable power producers will still struggle with merchant power pricing risk when securing financing for the development of new generation (other than those having long-term renewable energy credit contracts from the government). The capacity market model will represent only partial price stability, and only for the successful participants in the capacity market. In addition, the price volatility and co-variance experienced by wind power producers will continue to adversely affect the ability of renewable power developers to obtain the price hedges needed for long-term project financing. November 2016), online: $<$ https://www.theglobeandmail.com/news/alberta/alberta-moves-to-regulateelectricity-market/article33008740>.

Alberta Electric System Operator, "Participate in the REP," online: <https://www.aeso.ca/market/ renewable-electricity-program/first-competition/>.

102 Alberta Electric System Operator, "Alberta's Wholesale Electricity Market Transition Recommendation" (3 October 2016), online: <https://www.alberta.ca/documents/Electricity-markettransition-report.PDF>. 


\section{Overview of Canada's Federal Climate MANAGEMENT REgUlatory STRUCTURE}

Until December of 2016, Canada's provincial governments were adopting or abstaining from emissions reduction policies in the absence of a national climate change strategy. ${ }^{103} \mathrm{On}$ 9 December 2016, Canada's federal government announced its formal policy framework as the Pan-Canadian Framework on Clean Growth and Climate Change (the Federal Framework). ${ }^{104}$

The Federal Framework has four main pillars: (1) pricing carbon pollution; (2) complementary measures to further reduce emissions across the economy; (3) measures to adapt to the impacts of climate change and build resilience; and (4) actions to accelerate innovation, support clean technology, and create jobs. ${ }^{105}$ Carbon pricing is the central component of the Federal Framework. The Federal Framework's complementary measures include a phase-out of emissions from coal-fired electricity generation by 2030 (which is parallel to the target set by Alberta's Climate Leadership Plan), targeted reductions of methane emissions from the oil and gas sector by 40 to 45 percent below 2012 levels by 2025 (which is also comparable to the target set by Alberta's Climate Leadership Plan), and the introduction of regulatory performance standards for natural gas-fired electricity generation. ${ }^{106}$ Aside from the announcement of intent to implement these complementary measures, much of the remainder of the Federal Framework is stated in optimistic generalities and lacks the detail or funding to be meaningfully assessed.

As stated above, the crux of the Federal Framework is the announcement of a national carbon pricing floor. The benchmarks of the Federal Framework's carbon pricing include: (1) timeliness; (2) common scope; (3) revenue neutrality; (4) a federal backstop; and (5) legislated stringency floors. ${ }^{107}$ At present, Alberta's provincial regulatory structure meets or exceeds each tenet of the Federal Framework's carbon pricing policy.

Firstly, all provinces and territories must introduce carbon pricing by $2018 .{ }^{108}$ Between the SGER and the CLA, Alberta meets this requirement both for industrial emissions and enduser emissions.

Secondly, carbon pricing will be required to be applied to a common and broad set of emission sources across the economy "to ensure effectiveness and minimize interprovincial competitiveness." 109 Alberta's carbon levies apply to a broad list of specified gases, including

Canada was a signatory to the Paris Agreement, but no legislative framework was in place at the federal level to guide the provinces. Provinces thus began developing their own methods to address carbon emissions. For example, Quebec and Ontario have introduced cap-and-trade frameworks to address carbon emissions, while British Columbia implemented a carbon tax in 2008. See Paula Olexiuk et al, "Renewable Energy and Climate Change: Canada's New Frontier" (28 January 2016), Osler (blog), online: $<$ https://www.osler.com/en/resources/regulations/2016/renewable-energy-and-climate-changecanada-s-new $>$.

Office of the Prime Minister, "Communiqué of Canada's First Ministers" (Ottawa: PMO, 9 December 2016), online: <pm.gc.ca/eng/news/2016/12/09/communique-canadas-first-ministers>.

Federal Framework, supra note 1 at $2-3$.

Ibid at 11-19.

Ibid at 49 .

Ibid.

Ibid. 
carbon dioxide, methane, and other potent greenhouse gases. It is not anticipated that the Federal Framework will impose any additional requirements on the scope of provincial carbon pricing.

Further, the Federal Framework specifies that each jurisdiction can use carbon pricing revenues for their own needs, including climate change, clean transportation, and compensation of vulnerable communities. ${ }^{110}$ This is consistent with the Government of Alberta's pledge to keep the proceeds of the carbon tax in the province. Currently, the permitted uses of the provincial carbon levy are quite broad, including compensation of coal operators, direct rebates to consumers, investment in green technology and transit infrastructure, and even payment of government salaries and education programs. However, the permissive phrasing of the Federal Framework suggests that the uses of carbon levy proceeds currently contemplated by the Government of Alberta will not be constrained by federal legislation.

Moreover, if a jurisdiction does not have a system in place which meets the benchmarks set by the Federal Framework, the federal government intends to impose a backstop by imposing an explicit price-based system (that is, a federal carbon tax) and returning the proceeds to the non-compliant jurisdiction. ${ }^{111}$

The teeth of the Federal Framework's carbon pricing policy are contained in the pricing stringency floors. The federal strategy permits two system options — an explicit price-based system or a cap-and-trade scheme - each with legislated stringency floors. ${ }^{112}$ A province may adopt a cap-and-trade system akin to those in place in Ontario and Quebec; such jurisdictions must set a 2030 emissions reduction target at least equal to Canada's 30 percent reduction target, with more stringent annual caps through to 2022 which correspond to the projected emissions reductions from price-based jurisdictions. In the alternative, a province may adopt an explicit price-based system, such as British Columbia's carbon tax or Alberta's combination of CLA carbon levy and SGER performance-based carbon pricing model; such jurisdictions are required to have a carbon price of at least $\$ 10$ per tonne in 2018 , to rise by $\$ 10$ each year to $\$ 50$ per tonne in $2022 .{ }^{113}$ While Alberta has not legislated any carbon price escalator beyond its current $\$ 30$ per tonne level, Premier Rachel Notley has verbally committed to bringing the provincial carbon levy to the $\$ 50$ per tonne level by $2022 .{ }^{114}$

$\begin{array}{ll}110 & \text { Ibid. } \\ 111 & \text { Ibid. } \\ 112 & \text { Ibid. } \\ 113 & \text { Ibid. } \\ 114 & \text { Lewis, supra note } 44 .\end{array}$




\section{INTERPLAY OF REGULATORY SCHEMES BETWEEN LEVELS OF GOVERNMENT}

\section{A. FEDERAL FraMeWORK UNLIKELY TO IMPOSE SigNifiCANT ADDiTIONAL COSTS AND CONSTRAINTS ON ALBERTA INDUSTRY}

On the whole, the Federal Framework has not introduced any substantive measures which have not already been legislated or announced by the Government of Alberta. The federal government's announcement has made it very clear that it intends to be flexible and recognize carbon pricing policies already implemented in provincial jurisdictions. Therefore, the authors posit that not much additional cost will be borne by industry in Alberta as a result of the Federal Framework's carbon pricing policy. Of course, the imposition of a federal layer of regulations on gas-fired generation, methane leakage, fossil fuel subsidies (which the federal government aims to eliminate by 2025), vehicle emissions standards, and other regulatory measures mentioned in the Federal Framework could impose costs and operating constraints on Alberta's electricity and oil and gas sectors over and above their carbon costs and provincial regulatory compliance. The scope and impact of incremental federal regulation remains to be seen.

The Federal Framework is focused on collaboration with the provinces and territories in order to develop consistent and transparent reporting on the outcomes of carbon pricing policies, and to identify best practices to address the competitiveness concerns of emissionsintensive trade-exposed sectors, namely Alberta's energy sector. How that analysis will be conducted remains to be seen. However, an intention to ensure equivalence between provinces will likely lead to more common standard practices across jurisdictions to discourage so-called "carbon leakage," or the movement of carbon-emitting production processes to jurisdictions with more favourable carbon pricing. In this regard, the Federal Framework may correct a key shortcoming of the province's Alberta-specific regime. While a "made in Alberta" regulatory model was politically tenable at the time of the CCEMA's introduction, increasingly multi-jurisdictional industry players in Alberta's energy and electricity sectors need to be able to integrate their carbon strategies across markets. The collaborative approach to carbon pricing and other policy development announced by the Federal Framework may lead to the necessary integrative reforms.

\section{B. APPROPRIATENESS OF DUAL LAYERS of CARbon REgulation}

Leaving aside the practical impacts of carbon pricing under both the provincial Climate Leadership Plan and the Federal Framework, the flurry of government levels to demonstrate climate policy leadership raises the question of which level(s) of government may appropriately legislate to govern the carbon usage and pricing of their constituents. 
The Constitution Act, 1982 does not explicitly address climate change matters, though it does touch on governance of natural resources. ${ }^{115}$ As a result, the tension between federal and provincial authority over the regulation of greenhouse gases has never been conclusively resolved.

The federal government is incented to govern in this area in order to demonstrate its climate policy leadership in satisfaction of its international commitments, and in order to ensure that geographic areas or business sectors of national importance are not subject to competitive disadvantage or risk of carbon leakage.

However, legal scholar Peter Hogg has concluded that provincial legislation governing greenhouse gas emissions applying to operations within the province are constitutionally valid, on the basis of the property and civil rights governance power afforded to provinces in the Constitution Act. ${ }^{116}$ Alberta's position that the provinces, to the exclusion of the federal government, have the constitutional jurisdiction to regulate climate change is addressed in the preamble to the CCEMA, which states: "Whereas the Government of Alberta owns natural resources in Alberta on behalf of all Albertans and manages the exploration, development and production of renewable and non-renewable resources in Alberta." 117

Nevertheless, constitutional scholarship suggests that climate change legislation is also within the federal constitutional heads of power and, if structured as a carbon tax, that it is certainly within the federal government's right to levy any mode or system of taxation. ${ }^{118}$ The rules of federal paramountcy would cause provincial laws to yield to conflicting federal laws. While the federal government announcements appear to be eager to work collaboratively with the provinces to develop federal carbon pricing and climate change policies which complement those already in place in Alberta, a perceived unfavourable treatment of Alberta's carbon-intensive fossil fuel and electricity industries could create tension and uncertainty for companies operating within the province.

While it is an interesting legal issue, a constitutional standoff will likely never materialize. Regardless of the legal interpretation of constitutional authority, the federal government's practical jurisdiction over carbon pricing and carbon policies has become increasingly enshrined over time. The Federal Framework was developed in consultation with the provinces, territories, and Aboriginal communities, and was announced with provincial and territorial ministers present. Notably, all the provinces and territories other than Manitoba and Saskatchewan endorsed the Federal Framework. ${ }^{119}$ The authors posit that the federal and

Constitution Act, 1982, s 92A, being Schedule B to the Canada Act 1982 (UK), 1982, c 11 [Constitution Act $]$.

Peter W Hogg, "Constitutional Authority Over Greenhouse Gas Emissions"(2009) 46:2 Alta L Rev 507. CCEMA, supra note 3, Preamble.

Hogg, supra note 116 at 518, citing Constitution Act, supra note 115, s 91(3) ("“ $[\mathrm{t}]$ he raising of Money by any Mode or System of Taxation").

John Paul Tasker, "Trudeau Announces 'Pan-Canadian Framework' on Climate - But Sask, Manitoba Hold Off," CBC News (9 December 2016), online: <www.cbc.ca/news/politics/trudeau-premiersclimate-deal-1.3888244>. Saskatchewan has since signed on to an equivalency agreement with the federal government to avoid the coal phase-out requirement of the Federal Framework in exchange for the agreement to use additional renewable power production and additional use of carbon capture and storage technology: see "Saskatchewan, Canada Reach Equivalency Deal on Coal-Fired Power Plants," CBC News (28 November 2016), online: <www.cbc.ca/news/canada/saskatchewan/saskatchewancanada-reach-equivalency-deal-on-coal-fired-power-plants-1.3870843> . 
provincial governments have concurrent and overlapping legislative authority over climate policy, and the battleground may be in practical implementation rather than constitutional authority.

\section{INDUSTRY IMPLICATIONS: MANAGING CARbon Footprints on Shifting Policy Ground}

The Climate Leadership Plan and the largely parallel Federal Framework will indubitably impose additional costs, and in some cases flat-out restrictions, on Alberta's upstream oil and gas industry, the power generation industry, and private and public enterprises in all sectors. While the policy measures are new and the resulting regulatory structures are still evolving, one thing is clear - there has never been a greater incentive to develop effective carbon management strategies in Alberta.

\section{A. Carbon Auditing and Proactive Carbon Planning}

For the first time in Alberta, an incentive structure is being created to meaningfully reward companies for critically evaluating their operating structures and making reasonable investments towards carbon efficiency. Businesses in the province should conduct carbon audits on a corporate and project-by-project basis. Those that do so will be able to identify the areas in their design, equipment, or operating practices where they can most effectively manage their carbon costs.

After all, under the output-based allocation method to be imposed on large emitters currently subject to the SGER, the most carbon-efficient facilities within trade-exposed industries will be rewarded with emissions performance credits to carry over to the future or other emitting facilities, whereas the stragglers in the same industry who do not optimize their efficiency will be penalized with carbon levies. Compounded over several years, a disproportionate share of carbon costs within an industry will be borne by the least operationally efficient entities.

This incentive to critically evaluate a business and identify cost-effective ways of exceeding top-quartile performance benchmarks is not limited to the oil and gas industry. There is an opportunity for large industrial emitters across industries in Alberta to optimize their performance in pursuit of carbon competitiveness (and resulting lower SGER compliance costs) and make cost-efficient investments to minimize their costs in complying with the new climate policies. Large emitters in public capital markets are experiencing increasing pressure to formulate and communicate their carbon plans as part of their environmental and corporate disclosure.

Public and private entities with significant operating costs have already begun to aggressively audit the impact of the climate costs on their bottom lines. Hospitals, school boards, and municipalities in Alberta have begun to evaluate, and in some cases implement, plans to transition to light-emitting diode (LED) lighting, on-site solar power generation, 
greener transportation fuels, and other proactive carbon management plans to reduce their operating costs. ${ }^{120}$

One example of capital investment decision-making which stems directly from changing carbon legislation and proactive corporate carbon cost planning is the recent decision by TransAlta Corporation to accelerate their transition to clean power over and above the legislative requirements. ${ }^{121}$ The company currently operates a number of coal-fired generation facilities in Alberta which are subject to the mandatory coal phase-out imposed pursuant to the Climate Leadership Plan. As part of its proactive strategy, the company has announced that it will retire or mothball its least economically viable coal-fired facilities in advance of the statutorily required deadlines, and will accelerate the conversion of the remaining Sundance Units 3 to 6 and Keephills Units 1 and 2 to gas-fired generation to between 2021 and 2023. ${ }^{122}$ The strategy involves a capital cost of $\$ 300,000,000$ and is expected to extend the useful life of the heretofore coal-powered facilities past 2030, to be very competitive in the upcoming capacity market auctions, and to result in a 40 percent reduction in carbon emissions and associated carbon compliance costs. ${ }^{123}$ The accelerated conversion capital investment strategy is a powerful illustration of investment decisions being driven directly by recent climate change policy. Private and public entities, carbon emitters, and power generators alike can take note.

Similarly, ATCO Power has announced that it will retire its coal fleet before 2021 by converting certain or all of its coal plants to natural gas. ${ }^{124}$ While these conversions do not result in efficient conversion of natural gas to power, they will result in a dramatic reduction in the carbon footprints of these corporations, and the investments that each are proposing are certainly fueled by the reduction in carbon costs. The use of natural gas versus coal results in upwards of a 50 percent reduction in carbon production and, should the Alberta government eventually impose a $\$ 50$ per tonne carbon tax, one can easily determine that the carbon policy is likely the sole driver behind the proposed conversions.

Currently, Alberta power developers are actively considering the exposures that are being created as a result of carbon compliance. As power projects are long-term investments, the near-term uncertainty to the carbon regulations has a detrimental impact on the ability to make such long-term investments. The result is that many new large-scale power investments will likely be based on high efficiency natural gas-fired power plants. Stand-alone projects are expected to utilize large natural gas-fired turbines with high efficiency heat recovery systems deployed to achieve over 60 percent cycle efficiency. It is expected these units will not have any carbon exposure based on the rules that are currently being discussed, or at the

For example, Camrose County recently completed a high efficiency lighting retrofit of their administration building. The retrofit replaced all lighting in the building with LED troffer fixtures and is expected to save the county an average of $\$ 2,338$ and $23,388 \mathrm{kWh}$ per year. See Municipal Climate Change Action Centre, "Camrose County Administration Building Efficient Lighting," online: <www. mccac.ca/project-showcase/camrose-county-administration-building-efficient-lighting >. TransAlta Corporation, News Release, "TransAlta Board Approves Plan for Accelerating Transition to Clean Power in Alberta" (19 April 2017), online: <www.transalta.com/newsroom/news-releases/ transalta-board-approves-plan-for-accelerating-transition-to-clean-power-in-alberta/>. Ibid.

Ibid.

Geoffrey Morgan, "ATCO Aims to Speed Up End of Coal-Fired Electricity," Calgary Herald (11 May 2017), online: < https://www.pressreader.com/canada/calgary-herald/20170511/281530815941441>. 
very least, they will have mitigated exposure to a manageable quantity as they will be the most efficient plants.

Energy users that have significant heat loads, such as oil and gas producers involved in heavy oil, oil sands, or refining, will be able to earn significant benefits from merely having a large heat load. Cogeneration is the process where the heat load is served by capturing the energy from the exhaust gases of the gas turbine to provide a highly efficient energy system, approaching 85 percent or higher in total cycle efficiency. ${ }^{125}$ This will be a highly soughtafter base load operation for power projects in the future, as the high efficiency implies a significantly reduced carbon exposure, if any at all. Over the course of the next ten to 15 years, the Alberta electric system will likely be dominated by large combined cycle power plants and large industrial cogeneration projects. No large industrial operation is expected to be installed without a cogeneration facility included in its design on a go-forward basis. The landscape of power projects in Alberta will look significantly different from today within the next decade.

Even for facilities which are not able to identify quick fixes to improve their relative carbon competitiveness, a thorough carbon audit can help a company evaluate whether and to what degree capital or operational investments are worth making relative to their alternative costs of SGER compliance (that is, purchasing fund credits or emission offsets at the legislated or market rate, as applicable) or paying the carbon levy. Following a thorough carbon audit, an emitter may identify that capital investment or operational changes are optimal for managing its carbon emissions, or it may prefer capital investments in emission offset-generating projects which can be used to offset its carbon emissions or sold as a separate revenue stream. In any case, internal carbon planning and long-term carbon costing within an organization will facilitate the most effective investment decisions for individual entities.

\section{B. LEVERAGING TECHNOLOGIES}

The implementation of the Climate Leadership Plan presents an opportunity for oil and gas producers and power industry players to capitalize on technologies, either to minimize compliance costs or to generate additional revenue streams.

At present, the emission offset market has represented a minority of SGER compliance, in part because the ex post verification structure means that purchasers of registered emission offsets or emission performance credits may later discover that their purchase cannot be verified in accordance with legislated protocols, forcing them to spend on alternative SGER compliance options such as fund credits. While the emission offset verification and trading platforms are currently viewed as relatively opaque and insecure, renewable power producers or other entities which learn to minimize the transaction costs for offset verification and sale can benefit from a competitive advantage in a market whose per unit value will rise correspondingly to rising fund credit prices. For instance, Alberta-based startup ReWatt Power seeks to leverage technology to minimize this compliance risk for large emitters, by standardizing the data collected from emission offset-generating renewable power projects 
in accordance with the province's technical guidance for the applicable offset protocols, increasing verification transparency, and ultimately leveraging proprietary software to speed up the verification process and facilitate faster, more certain emission offset trading. ${ }^{126}$

Technology can also be leveraged to secure government funding of commercial and noncommercial projects. The ERA is tasked with finding and funding technologies and projects which reduce greenhouse gas emissions in Alberta. ${ }^{127}$ Since its first funding round in 2010, the ERA has invested a significant portion of its fund - funded from proceeds of fund credits bought under the SGER compliance scheme - into projects in a number of strategic areas, including renewable energy, energy efficiency, cleaner energy production and processing, and carbon capture and storage. In its 2015-2016 report, the ERA estimates that projects it has funded will reduce greenhouse gas emissions by more than $7 \mathrm{Mt}$ by $2020 .{ }^{128}$

As the fund credit price has been increased and is anticipated to keep escalating, and as emissions reductions targets have been made more rigorous, it is expected that the amount of money available in the ERA fund for research and development grants and for investment funding will increase with time. As is expected in a research- and development-heavy, technology-driven industry such as oil and gas exploration and production, many oil and gas producers have developed valuable technologies in-house. Oil and gas companies, or associated service companies, which develop commercially deployable technologies for the reduction of greenhouse gas emissions, can profit from those technological innovations by receiving ERA funding.

Renewable power producers are also able to compete for and receive ERA grant funding and commercial investment. The ERA has invested approximately $\$ 92,000,000$ in 19 renewable power projects to date, representing more than 28 percent of its investments. ${ }^{129}$ For instance, the ERA partly funded the development of the $300 \mathrm{MW}$ Blackspring Ridge wind project, the largest wind energy investment in Western Canada to date. ${ }^{130}$ The ERA also provides grant funding for the development of energy storage technologies, utility-scale solar projects, industrial energy efficiency solutions, and methane reduction systems. Importantly, ERA funding comprises a non-dilutive investment and can offer partial financing options for renewable projects that are not commercially competitive. As the ERA's investment pool

See online: ReWatt Power $<$ https://rewattpower.com/>.

ERA, “About ERA," supra note 16.

CCEMC, "Annual Report 2015/2016," online: <annual-report-2016.eralberta.ca/achievements>. For instance, New Sky Energy developed a resource recovery and waste treatment process that uses a nontoxic, water-soluble base to capture carbon dioxide and hydrogen sulphide contaminants from sour gas and convert them into by-products which are used to fabricate glass, paper, and other everyday products. In order to reduce the $3.5 \mathrm{Mt}$ of methane leaked from Alberta oil and gas wells each year, the ERA invested in a pilot project with Encana Corporation for its SlipStream technology, which captures the methane from gas vented from natural gas compression stations and feeds it back into the stream to help fuel the gas compressor, resulting in increased fuel recovery and a reduction of greenhouse gas emissions by more than 450,000 tonnes by 2020. ConocoPhillips has received funding for implementation of multiple technologies which reduce greenhouse gas emissions, including its REMVue fuel injection efficiency technology. The ERA also invested in Seal Well's technology that uses a bismuth-based alloy to seal oil and gas wells more effectively than the industry-standard concrete well seals, which deteriorate over time and leak methane.

Emissions Reduction Alberta, "Funded Projects," online: <eralberta.ca/projects/>.

Emissions Reduction Alberta, "Blackspring Ridge I Wind Project," online: <eralberta.ca/projects/ details/blackspring-ridge-wind-project/>. 
grows with the significant growth in fund credit prices, more and more funding will be available for investment in utility-scale renewable power projects.

Notwithstanding the investments by the ERA into certain power projects, Alberta's electric system will require tremendous investment over the next 10 to 15 years in order to keep abreast of not only aging fleet replacement, but also normal load growth. ${ }^{131}$ ERA investment, while welcome, is a small component of any large scale power investment and usually does not come into play while key decisions are being made. In any case, as a result of the need for a reduction of the carbon footprint, energy users and other private entities will likely develop those desirable in-house technologies to a commercial application and may be able to license those technologies or contract those services to their competitors to offset their own carbon compliance costs, or even generate a new profit centre.

\section{Investing in Renewable Power}

Investing in emission offset-generating projects, particularly new renewable power production, has never been as enticing to investor capital as it is now.

As cheaper electricity from coal is phased out of the electricity supply, renewable power producers will benefit from higher wholesale power prices, which should make new project economics more attractive to financiers. Renewable power producers who do not obtain indexed REC contracts from the AESO will also be able to sell their offsets in the private emission offset market, which additional revenue stream further bolsters a project's financeability, particularly for those offset generators which enter into long-term contracts to sell future emission offsets rather than only already-existing and registered offsets.

Evidently, as carbon compliance costs go up, purchasing emission offsets, and the source emission offset-generating projects, may become increasingly popular. As a result, public and private entities alike may consider various strategies for optimizing their stake in the emission offset market.

A number of oil and gas producers have chosen to generate in-house emission offsets, by developing their own renewable energy projects in the province. ${ }^{132}$ The rationale for oil and gas production or pipeline companies to invest directly in renewable energy or other offsetgenerating projects is multi-fold. Increasingly stringent reductions requirements and increasing fund credit costs will make emission offsets both more appealing and more costly. In-house development of offset-generating projects circumvents the current drawbacks of the private, bilateral emission offset market, namely incurring the transaction costs associated with finding emission offsetters, and purchasing, verifying, and retiring the registered offsets. Also, investing directly and publicly in popular renewable emission offset-generating

131 See Alberta Electric System Operator, "Renewable Electricity Program Recommendations," supra note 99.

132 Examples include: Nexen Inc. and TransAlta Corporation's joint ownership of the Soderglen wind farm in Fort Macleod, Alberta; Suncor Energy Products Inc.'s part-ownership in the Chin Chute and Magrath wind projects; and Enbridge Inc.'s stake in Blackspring Ridge, the largest wind farm in Western Canada, located in Vulcan County. In fact, Enbridge Inc. owns 16 wind farms across Canada, and its pipeline competitor TransCanada Corporation holds a diverse renewable portfolio composed of hydro, solar, nuclear, and wind power projects across the country. 
projects helps the oil and gas industry gain social licence, or at least better public relations than would result from privately purchasing fund credits or emission offsets from the registry. Furthermore, the oil and gas industry and renewables have a natural symbiosis, in that oil and gas producers often have investment capital, technological expertise, experience deploying large and capital-intensive energy projects, and pre-existing relationships in the communities where both types of projects tend to be located.

Direct investment in renewable energy projects to gain emission offsets and public relations benefits has been employed as a tool outside the oil and gas and pipeline industries as well. For instance, the furniture retailer Ikea has directly invested in two operating Alberta wind farms in order to publicly generate its volume power consumption as renewable energy. ${ }^{133}$ Municipalities and school boards in Alberta are also incented to invest in emission offset-generating renewable projects because of their relatively significant scale of carbon consumption and limited capacity for the transaction costs currently associated with emission offset trades. ${ }^{134}$

\section{Participation In The EMission OfFSet Market}

Some entities may not have the capital, core competencies, or interest in developing inhouse projects or investing directly in renewable power generators, but can still benefit from emission offset strategies in other ways.

For instance, a company with experience in hedging its natural gas production may want to branch out into buying "futures" in emission offsets, to capitalize on a belief that offset prices will rise at a different rate than currently predicted by the government or industry.

Furthermore, as emission offsets grow in value, there will be more companies and individuals who generate offsets but do not have the expertise or resources to verify or register them in commercial quantities. One of the criticisms of the emission offset generating system is that the protocols are difficult to understand and apply. A diversified resource company with community connections (to discover the farmers and other smallscale projects who are generating offsets in non-commercial quantities) and experience working within the province's regulatory regime could branch out into the offset aggregation business, such that they can cost-efficiently aggregate, verify, and sell (or use) emission offsets that otherwise would not have been brought to market. A number of aggregators have already begun operation in Alberta in recent years, after identifying transactional inefficiency and cost uncertainty as weaknesses in the current offset market, as well as identifying many small-scale emission offset generators. ${ }^{135}$

On the other end of the project scale spectrum, the commitment under the Federal Framework to facilitate collaboration with the provinces and territories portends an

133 “Ikea Canada Buying Second Alberta Wind Farm Near Drumheller,” CBC News (26 January 2017), online: <www.cbc.ca/news/canada/calgary/ikea-canada-alberta-wind-farm-drumheller-1.3953327>. See e.g. Ainslie Cruickshank, “Alberta Wind Farm Powers 500 Schools,” Edmonton Journal (21 August 2016), online: <edmontonjournal.com/news/local-news/alberta-wind-farm-powers-500-schools>. Alberta Agriculture and Forestry, "Lists of Aggregators," online: <www1.agric.gov.ab.ca/\$Department/ deptdocs.nsf/all/ofa15056/\$FILE/aggregators.pdf>. 
opportunity for large emitters in Alberta to leverage emission offset generation and trading mechanisms across jurisdictions in Canada to optimize their carbon management plans. Currently, large emitters subject to the SGER cannot apply emission offsets generated from renewable or other emission offset-generating projects in other jurisdictions. However, emission offsets generated in Alberta can be sold elsewhere, and the generators thereof can arbitrage Canadian and international jurisdictions for the best price. For instance, the Blackspring Ridge wind project referenced above is under a long-term contract to sell its renewable attributes to a Californian utility using such attributes to meet its foreign carbon compliance regulations. ${ }^{136}$

It should be noted that while the offset market in Alberta may appear to be of interest, unless there are long-term contracts to provide revenue certainty to the power project developers, emission offsets may be of marginal value. Long-term revenue certainty is the key that allows for new projects to be financed and installed, unless a large balance sheet financed player is prepared to take a long view of the Alberta marketplace. The proposed new capacity and energy market that is expected to be in place by 2021 appears to still rely on short-term agreements and may do little to promote new investments, other than from large balance sheet participants. Aside from the portion of renewable energy producers privy to a long-term contract with the AESO, a large portion of the new projects that will power Alberta's growth will have to contend with the emission offset market as an annual market.

For those entities which choose to participate in emission offset trading, either as a revenue stream or as a carbon compliance mechanism, it is important to note that Alberta's emission offset protocols are required to conform with the International Organization for Standardization platform ISO 14064-2 (ISO Standard). ${ }^{137}$ This allows for future integration with other offset markets that rely on the ISO Standard. For instance, British Columbia's Pacific Carbon Trust relies on the ISO Standard, ${ }^{138}$ and the Western Climate Initiative to which California, Quebec, and Ontario are party is also likely to be based on the ISO Standard. ${ }^{139}$ The strict and internationally recognized ISO Standard used for Alberta's emissions offset protocols means that the optimum size of offset-generating projects such as renewable power production is not constrained by the size of demand in Alberta's power market.

"Excess" offsets for which there is not an attractive market in Alberta can be sold in other jurisdictions, even though transmission issues in the province largely prevent excess energy from being sold outside the provincial market. Integration with a federal or regional climate initiative would offer a much broader market for both buyers and sellers of offsets. Renewable power producers would be remiss not to take advantage of a broad market of potential buyers. In addition, the volume of fund credits currently purchased from the

Greengate Power Corporation, News Release, "Greengate Power Receives Approval for 20-Year Power Purchase Agreements Totaling $450 \mathrm{MW}$ " (2 February 2011), online: <www.newswire.ca/news-releases/ greengate-power-receives-approval-for-20-year-power-purchase-agreements-totaling-450-mw507578691.html>.

137 See online: International Organization for Standardization $<$ https://www.iso.org/obp/ui/\#iso:std:iso: 14064:-2:ed-1:v1:en>.

138 Government of British Columbia, News Release, "Pacific Carbon Trust Delivers First Carbon Offsets" (21 July 2009), online: <https://archive.news.gov.bc.ca/releases/news_releases_2009-2013/2009ENV 0010-000126.htm>. 
government indicate that Alberta's emission offset market is not suffering from a shortage of demand, and can become more attractive as emission offset protocols, and the creation and verification process thereunder, become more transparent and user-friendly.

\section{E. Relying on Alternative Regulatory Structures}

In addition to the incentive to critically evaluate their facilities' performance relative to industry peers, smaller industry players also have the opportunity to evaluate which branch of the current policy structure benefits them the most. Currently, only large emitters with 100,000 tonnes or more of annual carbon dioxide or equivalent emissions are subject to the SGER emissions reduction requirements, ${ }^{140}$ although emitters with 50,000 or more tonnes of annual emissions must submit annual reports under the CCEMA legislation. ${ }^{141}$ The economywide carbon levy applies to all combusted fuels, with a few notable exceptions. In particular, direct emissions from the operation of a large emitter subject to the SGER are excluded from the economy-wide carbon levy. ${ }^{142}$

Since facilities subject to the SGER are only required to pay for emissions over and above their annual net emissions intensity limit, some oil and gas producers or other large emitters who are not currently subject to the SGER may opt into the regulation in order to avoid the blanket costs on all emissions imposed by the CLA. There are many facilities which do not meet the 100,000 tonne threshold of a large emitter but are still required to be familiar with and comply with the reporting requirements of the SGER framework pursuant to the CCEMA's reporting regulation. These facilities may benefit from opting into the SGER regulatory framework in order to avoid paying for emissions below their net allowable emissions intensity on which they would otherwise be taxed pursuant to the CLA. For instance, municipalities, hospitals, and school boards have relatively significant carbon consumption, and possibly the administrative staff and resources to warrant opting into SGER.

The reason this option may not be for everyone is that opting into SGER comes with administrative, reporting, and compliance costs which not every fuel consumer can bear. Further, while dual-stream carbon pricing is in place until at least 2018, the provincial government may eventually eliminate this alternative by adopting the Climate Change Advisory Panel's proposed Carbon Competitiveness Regulation, a single regulation which applies carbon levies to both industrial emissions from large emitters and end-use emissions applicable to the wider economy. ${ }^{143}$

That said, becoming subject to the SGER structure is not the only exemption from the CLA's broad-based carbon levy applicable to all emissions on which oil and gas producers or associated industry players can rely. For instance, the Climate Leadership Regulation exempts oil and gas producers from paying the carbon levy on fuel that is used in a

\footnotetext{
140 SGER, supra note 4, s 2(a).

141 See AEP, "Specified Gas Reporting Standard," supra note 11.

142 CLR, supra note 79, s 11(1). See also Government of Alberta, "Carbon Levy Fuel User Exemption Application (AT5102) Instruction Guide,” online: <www.finance.alberta.ca/publications/tax_rebates/ carbon-levy/forms/CL-Exemption-Guide.pdf>. 
production process before 2023, whether that fuel is flared, vented, or otherwise used, where production processes include any activity integral to the operation of an oil or gas well, among other activities. ${ }^{144}$ Where an oil producer does not have a license to flare, it must have an alternative way to channel the flare gas, including through gathering and electricity generation at an on-site power plant, the electricity from which can be used to power operations (reducing electricity costs) or sold into the provincial power grid (creating an additional revenue stream to offset carbon costs). Since the producer could not operate without an appropriate alternative to flaring, an on-site power production process could be considered integral to the continued operation of the oil well, and therefore exempt from the carbon levy. This presents an opportunity for behind-the-fence power producers to apply for an exemption from the CLA and, due to scale of emissions, also be exempt from the SGER.

\section{Conclusions}

Carbon management has become a major policy initiative at both the federal and provincial levels. In Alberta, greenhouse gas emitters will be challenged to find the most efficient and cost-effective ways to comply with the diverse and still-evolving regulations which apply to them. For some, these regulations also present significant opportunities for the market-supported or government-supported development of renewable power production, operational efficiencies, or other profitable programs. Industrial greenhouse gas emissions from Alberta facilities represent a significant share of the national total due to the province's large energy industry and electricity base. As a result, the strategic reactions of Alberta's fossil fuel and electricity industry participants to Alberta's climate policy framework will be important in shaping practical and legal outcomes for the nation as a whole. 